\title{
CURRENT EFFORTS AND PROPOSALS TO REDUCE HEALTHCARE COSTS IN SERBIA
}

\author{
Mihajlo Jakovljevic ${ }^{1}$, Mirjana Jovanovic ${ }^{2}$, Zorica Lazic ${ }^{3}$, Vladimir Jakovljevic ${ }^{4}$, Aleksandar Djukic ${ }^{5}$, Radmila Velickovic ${ }^{6}$, Mirjana Antunovic ${ }^{7}$ \\ ${ }^{1}$ Department of Pharmacology and Toxicology, The Medical Faculty University of Kragujevac \\ ${ }^{2}$ Department of Psychiatry, Clinical Centre Kragujevac \\ ${ }^{3}$ Department of Internal Medicine, Center for Lung Disease, Clinical Centre Kragujevac \\ ${ }^{4}$ Department of Physiology, the Medical Faculty University of Kragujevac \\ ${ }^{5}$ Department of Internal Medicine, Center for Endocrinology, Diabetes and Metabolism, Clinical Centre Kragujevac \\ ${ }^{6}$ Department of Pharmacy, the Faculty of Medicine, University of Nis \\ ${ }^{7}$ Institute of Pharmacy, Military Medical Academy Belgrade
}

\section{SADAŠNJI NAPORI I PREDLOZI ZA OGRANIČENJE TROŠKOVA ZDRAVSTVENE ZASTITE U REPUBLICI SRBIJI}

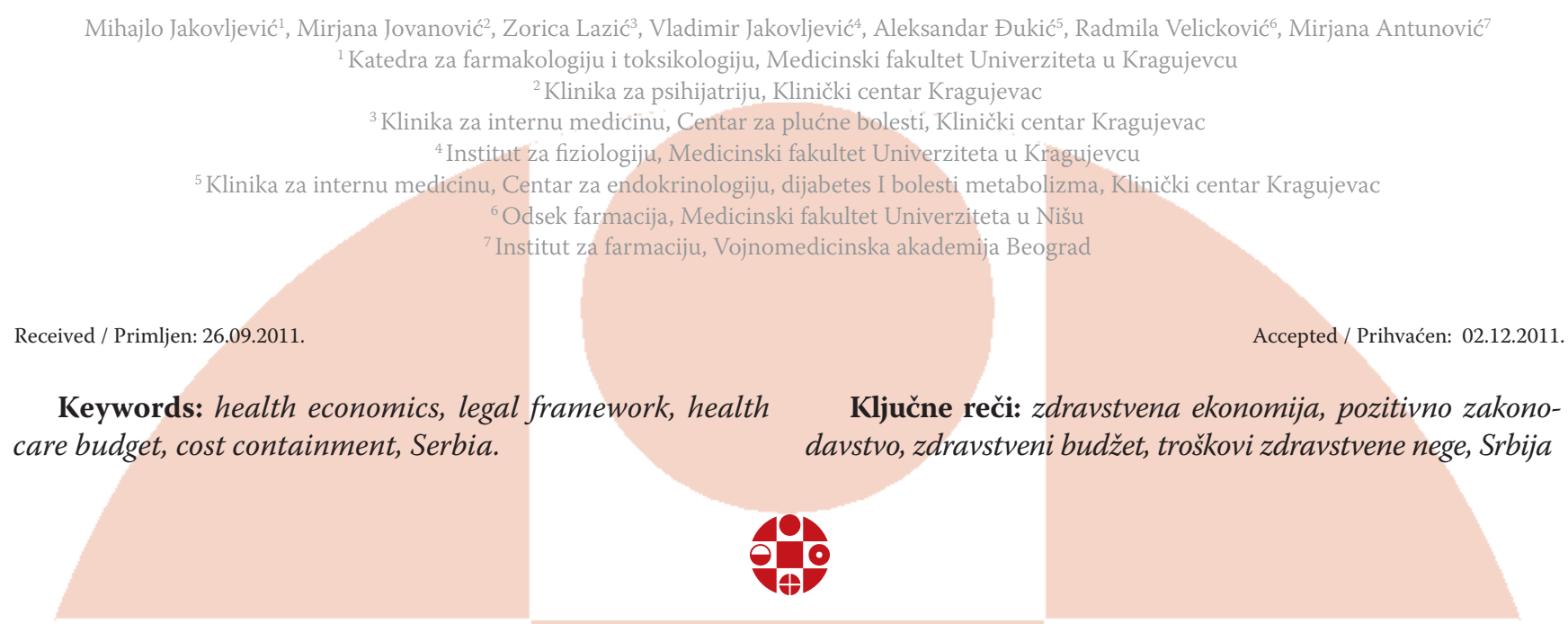

\section{FUNDING AND REIMBURSEMENT OF HEALTH CARE SERVICES IN SERBIA}

During the past few decades, health care decision makers have become aware of rapidly increasing health care expenditures in most northern hemisphere economies. National drug agencies worldwide, headed by the developed pharmaceuticals market, have accepted economic health assessments, acquired through clinical trials, as necessary evidence for marketing new drug approvals.

The health system in Serbia is financed by one core fund, which consists primarily of compulsory medical insurance taxes on the employed population. Most inpatient care, which accounts for more than half of the expenditures, is provided by a contract between the Republic Health Insurance Institute and clinical facilities (1). According to purely economic criteria, most of the institutions responsible for providing public sector services in southeastern European middle-income economies show more than modest performance. The limited availability of reimbursement for various treatment options requires pharmacoeconomic evidence for decision making. The national Health Insurance Fund has created two boards for this purpose. The first board is the Central Experts Committee on Medicines, and the second board is the Pharmacoeconomics Committee. These boards decide on the inclusion of specific drugs in the positive reimbursement list based on evidence from foreign pharmacoeconomic assessments, mostly Cochrane reviews and NICE reports. The conclusions of these systematic reviews and meta-analyses of the comparative cost effectiveness of medicines are developed within the complex hierarchy of the United Kingdom's NHS. Unfortunately, these conclusions are usually not directly transferable to the clinical setting of the western Balkans. ICER's must be recalculated, and many equations must be adjusted. The main argument in favour of these adjustments is the substantially cheaper labour force, which is sufficient to move the assessment significantly in one direction. Another argument is the "willingness to pay" threshold. Its current value is assessed at $€ 14,500$ in Serbia and at $€ 39,000$ in Britain per life year gained.

The statements of the aforementioned committees can significantly impact the local drug pricing process. Recently, some tertiary care hospitals, particularly the hospital in the city of Kragujevac, have imposed a mandatory internal procedure when introducing new drugs. This formulary on drug acquisition criteria requires drug candidates to provide pharmacoeconomic justification and a budget impact analysis as an appropriate step forward. 


\section{SEARCHING FOR LOCAL EVIDENCE - DOMESTIC RESEARCH EFFORTS IN PHARMACOECONOMICS}

The main domestic sources of research and reliable local evidence are state-owned universities. A Thomson Reuters ISI report in July 2011 called Serbia as the dominant country among countries considered "rising stars" in terms of their number of published and indexed ISI research papers. These developments began in 2002 with the introduction of one of the earliest evidence-based medicine programmes as part of an undergraduate curriculum of medicine in a university in the Western Balkans. Approved financing was available for two consecutive four-year cycles of projects on pharmacoeconomics in 2006-2010 and 2011-2014. Both of these projects provided financial resources for further research. The home institution assisted these local efforts by forming the only Internal Research Fund in Serbia, providing up to 25,000,000 CSD through smaller-scale "junior" research projects.

These contributions by the Ministry of Science and Technological Development and the Medical Faculty in Kragujevac have allowed for the successful publication of several pharmacoeconomic trials. Some of these cost evaluations in clinical settings have examined patients suffering from diabetes mellitus type 2, chronic obstructive pulmonary disease, alcohol addiction, rheumatoid arthritis, haemodialysis, preterm labour management and other medical conditions that have the most significant budgetary impact in the domestic health care setting (2-5). Some of these analyses were designed as classical cost of illness analyses, others were designed as comparative economic evaluations (cost/utility and cost/effectiveness trials) and the remaining analyses used an in-depth modelling approach with TreeAge commercial software. One of the positive domestic developments in the field is the recent publication of the first pharmacoeconomic guidelines in the Serbian language on behalf of the Serbian Pharmaceutical Chamber. In this context, it is necessary to mention two consecutive cycles of the World Bank's substantial investment in projects on capacity building, from 2005-2007, and the systemic implementation of the Health Technology Assessment (HTA) in Serbia, in 2007-2008. Larger-scale changes have also been initiated by the Serbian Government and the Ministry of Health within the framework of the "Serbia Health Project", for which two steps were planned. The first step was the "Feasibility Study on HTA Agency in Serbia", and the second step was the "Basic Benefit Package on the Way towards Evidence-Based Health Care in Serbia".

These and other ongoing efforts throughout the country contribute to a healthy core and to achieving a critical mass of awareness on the necessity of pharmacoeconomic evaluation in local conditions. We must mention that the process is still underway and that our country has no formally established HTA agency, unlike many middleincome new EU members (such as Hungary, Poland, and Latvia). Only a significant investment of money, time, and human resources as well as wise management can provide the long-term basis for the reasonable allocation of resources and evidence-based health care in a small, uppermiddle-income market in the EU economic zone.

\section{RECOMMENDED LEGAL FRAMEWORK CHANGES TO FACILITATE FURTHER DEVELOPMENTS}

Serbia's national health care expenditure, expressed as a percentage of the nominal Gross Domestic Product, falls well below the Organization for Economic Co-operation and Development (OECD) average. Although Serbia has a comparatively modest mature pharmaceutical market, it has recently experienced rapid growth. The value of drug turnover in the market has increased up to three times in terms of unit consumption. This increase is explained by the decline of domestic currency in favour of the euro and decreasing prices in the nearby "reference markets".

Due to insufficiently established administrative procedures for examining cost effectiveness, there is still room for improvement. We should base the strategic changes in our national health policy on the experiences of the huge health care markets worldwide, which have gained substantial historical experience with the weaknesses of a market-oriented economy. According to contemporary health economists, Serbia's current legislative framework for approval of new drugs and medical technologies should be adapted in several ways:

- We should expend every effort to provide contracting between small and medium private health care facilities and the governmental Health Insurance Fund in charge of financing public medical care delivery;

- We should downregulate the administrative procedures and taxes necessary for academic unsponsored clinical trial approval;

- Under the current circumstances, the legislative framework for drug-related clinical trial approval imposes significant expenses and long delays on academia, effectively serving to limit biomedical research activity in Serbia without improving patient protection;

- Because we currently have two professional associations in the field, the Pharmacoeconomic section of the Serbian Pharmaceutical Society and the International Society for Pharmacoeconomics and Outcomes Research - Chapter Serbia, whose members mostly belong to one of these associations, we believe that much more horizontal and vertical networking is required;

- There is a need for the acquisition and dissemination of economic evidence, particularly by including the basics of pharmacoeconomics in undergraduate curricula of pharmacy and medicine studies; and, above all,

- Introducing "the fourth hurdle", evidence on cost effectiveness as a requirement during submission for new drug and/or medical technology approval for marketing.

It is clear that a society with scarce resources cannot afford to prioritise the reimbursement of health goods and services based on any criteria other than a straightforward analytical framework. Policy makers will come under increasing pressure to comply with these matters during the EU accession policy. It can be assumed that the harmonisa- 
tion of health care legislative requirements will follow a similar trend. Espicom Business Intelligence released its latest report on Serbia's pharmaceutical market in October 2011. It assumes that overall economic recovery and increased health care spending, which is currently the highest in the region (expressed as a percentage of the Gross Domestic Product), will boost further development after the recessional slowdown of 2009. We must further develop our own research efforts aimed at economic assessments of medical technologies. We must also identify a unique formula to achieve complementary roles between academia, policy makers and the pharmaceutical industry. Although these groups work on different sides, they have the common goal of the greatest possible quantity and quality of health for the nation with the available resources.

We believe that we must search for our own middle way while observing older health care systems that learned difficult lessons from market economy weaknesses that we may be able to avoid.

\section{ACKNOWLEDGMENTS}

The authors would like to express their gratitude to the Ministry of Education and Science of the Republic of Serbia for Grant OI N ${ }^{\circ} 175014$ and for the Medical Faculty Univer- sity of Kragujevac Junior Internal Research Grants number $17 / 10$ and $08 / 08$, from which the clinical trials that served as the basis for this Letter to the Editor were jointly funded.

\section{REFERENCES}

1. Gajic-Stevanovic M, Vuksa A, Zivkovic S, Teodorovic N. Cost of Primary Health Care in the Republic of Serbia for the Period 2006-2008. Serbian Dental Journal 2010; 57: 86-97.

2. Biorac N, Jakovljević M, Stefanović D, Perovic S, Janković S. Assessment of diabetes mellitus type 2 treatment costs in the Republic of Serbia. Vojnosanit Pregl 2009; 66: 271-6.

3. Jovanovic M, Jakovljevic M. Inpatient Detoxification Procedure and Facilities: Financing Considerations from an Eastern European Perspective. Alcohol Alcohol 2011; 44: 547-54.

4. Perović S, Janković S. Renal transplantation vs hemodialysis: cost-effectiveness analysis. Vojnosanit Pregl 2009; 66: 639-44.

5. Jakovljevic M, Varjacic M, Jankovic SM. Cost-Effectiveness of Ritodrine and Fenoterol for Treatment of Preterm Labor in a Low-Middle-Income Country: A Case Study. Value Health 2008; 11: 149-53.

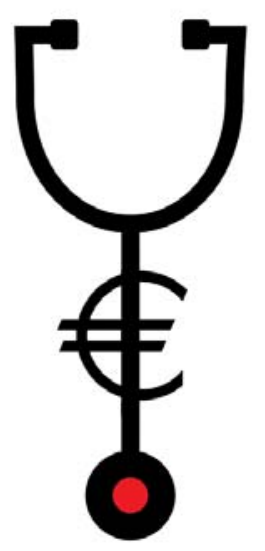

